\title{
O espaço do texto literário na Base Nacional Comum Curricular na etapa do Ensino Fundamental
}

\author{
The space of the literary text in the Base Nacional Comum Curricular \\ in the stage of Fundamental Teaching
}

\section{Ana Paula Teixeira Porto \\ Luana Teixeira Porto}

Universidade Regional Integrada do Alto Uruguai e das Missões - URI - Frederico Westphalen - Rio Grande do Sul - Brasil

\begin{abstract}
Resumo: Considerando-se a relevância da leitura de textos literários para a formação humana e para o desenvolvimento do hábito de leitura e a necessidade de se oportunizar, na Educação Básica, o acesso ao texto literário e a práticas leitoras que possam despertar a fruição estética e a proposição de sentido para os textos lidos, este artigo discute uma recente orientação do Ministério da Educação (MEC) para o ensino fundamental brasileiro e avalia a perspectiva sobre a literatura constante no documento. Trata-se da Base Nacional Comum Curricular - BNCC, aprovada em 2017, e que deve nortear a prática docente do primeiro ao nono ano do ensino fundamental em escolas públicas do país. Interessa, sobretudo, discutir a concepção de ensino de literatura na BNCC e avaliar a proposição de abordagem na segunda etapa do ensino fundamental $O$ estudo toma por base reflexões sobre relações entre ensino e literatura e analisa o documento do MEC, apontado no artigo como elemento que ratifica um crescente apagamento do espaço da literatura na formação escolar.
\end{abstract}

Palavras-chave: Texto literário, BNCC, Ensino fundamental.

Abstract: Considering the relevance of the reading of literary texts for human formation and for the development of reading habits and the need to provide access to the literary text and reading practices that can awaken aesthetic enjoyment in Basic Education and the proposition of meaning for the texts read, this article discusses a recent orientation of the Ministry of Education (MEC) for Brazilian elementary education and evaluates the perspective on literature in the document. It is the National Curricular Common Base Base Nacional Comum Curricular - BNCC, approved in 2017, and which should guide the teaching practice from the first to the ninth year of elementary education in public schools in the country. It is particularly interesting to discuss the conception of literature teaching at the BNCC and to evaluate the proposition of approach in second stage of elementary school. The study is based on reflections on the relationship between teaching and literature and analyzes the document of the MEC, pointed out in the article as an element that ratifies a growing erasure of the space of literature in school education.

Keywords: Literary text, BNCC, elementary school. 


\section{Considerações iniciais}

As relações entre literatura e escola, no contexto da Educação Básica no Brasil, expõem fissuras relacionadas a questões teóricometodológicas sobre ensino de literatura e mediação de leitura de texto literário na sala de aula. Essas frinchas apontam um descompasso entre perspectivas teórico-metodológicas defendidas por grande parte de estudiosos que buscam resguardar o valor social e estético da literatura enquanto bem cultural a ser preservado e reconhecido no ambiente formativo com vistas à interação entre texto e leitor (e a consequente atividade de construção de significado para a matéria lida) e ações concretas executadas em educandários que, não raramente, exploram o "caráter utilitário" da literatura, colocando-a como meio para discussão de valores morais ou aprendizagem de elementos linguísticos.

Nesse âmbito, é oportuno pontuar que o ensino de literatura e a leitura na escola no Brasil historicamente enfrentam problemas que refletem a chamada crise de leitura que denuncia dados alarmantes acerca do nível de leitura dos estudantes na Educação Básica, como provam dados do PISA e do SAEB. No que tange especificamente ao ensino de literatura, avolumam-se críticas relacionadas a diversos fatores, como: a) ao processo de escolarização ou "didatização" do texto literário, marcado pela tendência de abordagem do texto literário como pretexto para apreensão de regras gramaticais da língua ou de compreensão de um dado momento histórico; b) ao tratamento do texto literário por meio do estudo da periodização literária, que restringe o conhecimento sobre literatura à apreensão de características de estilos de época literária e identificação, em obras e autores, da aderência a esses estilos, minimizando a interpretação do texto propriamente dito; c) à seleção de obras para leitura na escola, muitas focadas no estudo de autores canônicos, o que minimiza a chance de o estudante conhecer autores e obras que não fazem parte do círculo dominante de recepção literária; d) à abordagem do texto literário sem consideração à sua natureza intertextual e plurissignificativa, prática que reduz a possibilidade de pôr em diálogo obras de diferentes autores e tempos históricos e possibilidades múltiplas de interpretação de um mesmo texto; e) ao uso inadequado de ensino de literatura baseado no exame de fragmentos de texto em detrimento da leitura integral da obra; f) ao descompasso entre a recente produção em teoria e crítica literária e o ensino de literatura nas salas de aula.

Todos esses aspectos que assinalam a precariedade do ensino de literatura na escola e a abordagem inadequada do texto literário em aulas de leitura revelam ainda haver divergência entre os documentos que norteiam o ensino no Brasil e aquilo que estudos críticos consideram adequado em relação à presença do texto literário na sala de aula. De um lado, há proposições orientadoras do Ministério da Educação (MEC) para a abordagem do texto literário na sala de aula e aquilo que grande parte dos pesquisadores considera adequado para o tratamento e o espaço dessa expressão artística. Como exemplo de trabalhos que discutem meios de inserção da literatura na sala de aula, citam-se proposições de Regina Zilberman (1982; 2005), Maria da Glória Bordini (2005), Arnaldo Franco Júnior (2015).

Entre os documentos norteadores, está a recente Base Nacional Comum Curricular - BNCC, aprovada em 2017, a qual trata das habilidades e competências a serem reveladas na Educação Básica, nos níveis da Educação Infantil e Ensino Fundamental. Dessa forma, torna-se oportuno apontar a concepção de ensino de literatura subjacente a esse texto bem como refletir sobre o que esse documento prevê como obrigatório de ser abordado na sala de aula quando se trata de texto literário e quais as diretrizes metodológicas são expostas para fazer (ou não) do texto literário elemento presente de apreciação e interpretação no cotidiano formativo do estudante brasileiro.

Considerando-se a relevância da leitura de textos literários para a formação humana e para o desenvolvimento do hábito de leitura e a necessidade 
de se oportunizar, na Educação Básica, o acesso ao texto literário e a práticas leitoras que possam despertar a fruição estética e a proposição de sentido para os textos lidos, assim como a formação do leitor, este artigo analisa o espaço indicado na Base Nacional Comum Curricular ao estudo e à leitura do texto literário na etapa do Ensino Fundamental. Para essa discussão, abordam-se também relações entre ensino e literatura, mais especificamente estudos teórico-críticos que discutem o valor da literatura como bem cultural e como objeto de apreciação na formação escolar com vistas à educação literária.

\section{A formação de leitores de literatura nas escolas}

Quando se pensa em uma perspectiva intercultural e interdisciplinar para a formação de leitores (e não apenas de leitores de literatura) nos contextos escolares, deve-se levar em conta algumas considerações. A leitura de textos de natureza diversa precisa ser priorizada nessa formação, pois, como preconizam os Parâmetros Curriculares Nacionais PCNs (1997; 2000), ao aluno deve ser proporcionado o contato com gêneros diversos, orais e escritos, não apenas para exercício da leitura, mas também como forma de consolidar a prática de escrita. Ao tornar a leitura um objeto de aprendizagem, a escola deve estimular o aluno a perceber a natureza de cada gênero, sua complexidade e as relações que estabelece com outros. Dessa forma, a formação de leitores exige a construção de competências relativas ao conhecimento de cada forma de elaboração de texto e os diálogos que este pode estabelecer com outros, de gênero diverso ou não ou de contextos de produção simulares ou não, o que consolida a perspectiva intercultural e interdisciplinar.

Nesse processo de formação de leitores, também é oportuno considerar que "quando os alunos não têm contato sistemático com bons materiais de leitura e com adultos leitores, quando não participam de práticas onde ler é indispensável, a escola deve oferecer materiais de qualidade, modelos de leitores proficientes e práticas de leitura eficazes" (PCNS,
1997, p. 37), o que requer que professores estimulem a leitura fora do ambiente escolar e façam os alunos perceberem que a leitura não é uma atividade que o professor pede e que "vale nota", mas que é indispensável para sua formação, para o seu conhecimento de mundo, para sua inserção em outros contextos. Para que essa formação seja possível, como já salientado por Zilberman (1988), é dever da escola despertar o gosto pela literatura, 0 que pode ser explicado por pelo menos duas razões: pela capacidade que o texto literário apresenta de suscitar a imaginação, a criatividade, a descoberta de contextos distintos a partir da fruição poética e estética; e pela potencialidade de nos fazer pensar e refletir sobre o mundo, ampliando nossos horizontes de leitura.

Além de despertar a atenção do aluno para a literatura, é preciso reconhecer que ela deve ser abordada a partir de uma perspectiva intercultural, o que significa não se restringir à leitura de textos literários de um contexto cultural apenas, mas da interação entre textos de culturas diversas que permita, entre outros, uma perspectiva de leitura de textos produzidas em épocas e contextos diversos não apenas do Brasil. Sinaliza-se a relevância, então, de uma abordagem da literatura focalizada na linguagem de sua composição e no diálogo com outras linguagens, tendência já apontada pelos Parâmetros Curriculares Nacionais para o Ensino Médio (2000) quando ressaltam que a área de linguagens deve considerar as linguagens de forma inter-relacionada, amparadas em diversos suportes inclusive os midiáticos dada a relevância atribuída às tecnologias - e correlacionadas às práticas sociais e à história.

Outro pressuposto nessa perspectiva relaciona-se ao perfil do professor, a sua formação e a sua prática. Embora pesquisas constatem as fragilidades de formação e de leitura de alunos que ingressam nos cursos de formação continuada e que haja problemas de abordagem da literatura no decorrer da graduação ${ }^{1}$, o que acarreta também

\footnotetext{
1 Pesquisas divulgadas por Sanches (s.d) apontam diversas fragilidades no processo de formação de professores, como cursos superiores com qualidade questionável, dificuldades de
} 
dificuldades de desenvolvimento de práticas de leitura eficazes e eficientes nas escolas, o professor de literatura precisa superar fragilidades e buscar desenvolver estratégias de leitura de literatura no diaa-dia escolar. Como destaca Berenblum (2006, p. 28), não basta apenas um professor que leia, mas um professor capacitado para fazer com que os alunos gostem de ler e sejam proficientes nessa competência:

Não se trata de um professor que apenas "leia", mas de um professor que leia com competência e autonomia, capaz não apenas de incentivar seus alunos, mas de mostrarIhes as sutilezas e entrelinhas dos textos, em especial dos textos escritos.

Para isso, faz-se imperativo que o professor seja um leitor não só de textos canonizados, eleitos pela historiografia como sendo exemplares, mas também de textos que circulam no contexto dos alunos e que nem sempre figuram no rol daquilo eleito para ser lido. Refere-se nesse sentido à necessidade de o professor conhecer textos literários recentes, populares e não clássicos (no sentido canônico), como os de John Green e J. K. Rowling ${ }^{2}$ que aparecem como um dos mais lidos pelos jovens brasileiros, e tornar esses textos objetos de práticas de leitura. Essa perspectiva assinala uma aproximação das práticas de leitura aos interesses dos jovens, estimulando-os a ler para que, familiarizados com esses gêneros, possam motivar-se para ler também os clássicos.

Ainda vale destacar que, se for considerado o perfil discente que as escolas estão recebendo - os alunos nativos digitais ${ }^{3}$-, tem-se de pensar em

acesso às bibliografias, repetição de conceitos de historiadores nos cursos de literatura e pouca análise de texto, priorizando-se o estudo das escolas literárias, são fatores que denotam o despreparo dos cursistas de Letras para atuação profissional.

2 As obras desses escritores são apontadas em rankings de livrarias e de revistas e blogs como os textos mais vendidos, lidos e comentados nas redes sociais, o que assinala uma preferência por obras estrangeiras e não brasileiras quando o assunto é a leitura de livros de ficção, assim como um gosto pela literatura produzida recentemente.

${ }^{3}$ Nativos digitais é um termo usado para referir-se àqueles que nascerem e cresceram, usando diversos dispositivos tecnológicos (computadores, celulares, videogames, ipod, MP3, tablets, etc) e tendo maior familiaridade com esses recursos. Caracterizam-se também por valorizar a aprendizagem estratégias de formação de leitores e formação cultural que deem conta dessa clientela. Insistir na leitura de textos clássicos como primeiro passo para a estimulação da leitura literária nesse contexto parece ser um contrassenso, que acarreta maior desgosto da leitura literária e associação à literatura como algo enfadonho e desprazeroso. Da mesma forma, uso de metodologias tradicionais de leitura, com foco no esquema repetitivo de leitura - texto - exercício, mostra-se não plenamente adequado.

Com os nativos digitais, tem-se também a presença de leitores que concebem a literatura como uma mercadoria que necessita de simplificação e que precisa da rapidez narrativa que se encontra no cinema e na televisão. Conforme descreve Bosi, há um gosto por textos de linguagem simples e leitura imediata, superficial:

O indivíduo-massa, a personalidade construída a partir da generalização da mercadoria, quando entre no universo da escrita (o que é um fenômeno deste século), o faz com vistas ao seu destinatário, que é o leitor-massa, faminto de uma literatura que seja especular e espetacular. Autor e leitor perseguem a representação do show da vida, incrementado e amplificado. Autor-massa e leitor-massa buscam a projeção direta do prazer ou do terror, do paraíso do consumo ou do inferno do crime uma literatura transparente, no limite sem mediações, uma literatura de efeitos imediatos e especiais, que se equipare ao cinema documentário, ao jornal televisivo, à reportagem ao vivo (...) o filme, imagem em movimento, teria tornado supérflua, para não dizer indigesta, a descrição miúda (...) Uma cena de um minuto supriria, no cinema, o que o romancista levou mais de uma dezena de páginas para compor e comunicar ao seu leitor (BOSI, 1994, p.109110).

Nesse contexto de desafios à prática docente, resta reconhecer que a maior dificuldade não está na presentificação do texto literário na escola, mas na adoção de recursos metodológicos que podem aproximar o aluno do texto, fazendo com que o primeiro goste de apreciar o segundo, propondo sentido e vendo sentido no que lê. Assim, tão oportuno quanto discutir as relações entre leitura e

colaborativa, preferir informações provenientes de diversas multimídias, além de interagir e ficar na rede ao mesmo tempo em que realizam outras atividades. 
ensino é clarificar a perspectiva que fundamenta e constitui o trabalho com o texto literário na sala de aula. E uma das orientações para a abordagem do texto literário na escola está na recente Base Nacional Curricular Comum.

\section{A BNCC e o espaço do texto literário na etapa do Ensino Fundamental}

A Base Nacional Curricular Comum referente ao Ensino Fundamental foi aprovada em 2017, constituindo-se em nova fonte de orientação de propostas pedagógicas das escolas, de seus currículos e, por consequência, de planejamento de professores em todas as áreas formativas, e fazendo supor que "os docentes não sabem o que fazer nas escolas sem uma orientação curricular comum." (LOPES, 2018, p. 23). O documento, no texto de apresentação do então ministro da educação Mendonça Filho, pontua que se "inicia uma nova era na educação brasileira e se alinha aos melhores e mais qualificados sistemas educacionais do mundo." (2017, p. 2) - uma afirmação que precisa ser questionada, uma vez que não estão explicitadas quais são as referências em educação no mundo e em que sentido o Brasil pode se inserir nesse conjunto exemplar, tendo em vista sua história e características locais bem como suas condições de promoção de uma educação de fato qualificada.

Ao se ler o texto da BNCC, é possível constatar que a proposta dá continuidade ao que já há na Matriz de Referência do ENEM, nos PCNs e na LDBEN, portanto, não se inicia uma "nova era" na educação brasileira. Pelo contrário, a BNCC ratifica algumas perspectivas educacionais já conhecidas e cujos resultados, como sabemos, são insuficientes e muito longe de uma educação qualificada. Dessa forma, o novo texto, de caráter normativo, apenas reforça antigas perspectivas de sistematização da educação básica, recusando-se a uma proposição inovadora e que de fato possa espelhar-se em modelos exitosos de países desenvolvidos.

Nessa perspectiva, a base dá sequência ao projeto educacional dos PCNS e da Matriz de Referência do ENEM em vários sentidos: segmenta os conhecimentos em cinco grandes áreas, definindo competências e habilidades a serem desenvolvidas em cada uma delas e indicando, de forma mais indireta, quais conteúdos são imprescindíveis à formação básica. O documento insiste na concepção de que é preciso haver um currículo comum para todos, apresentando um "projeto de uma base unificadora e homogeneizadora, sob o argumento de que a qualidade da educação depende desse projeto." (LOPES, 2018, p. 26).

A BNCC ainda assegura a valorização de competências, mesmo que gerais, associadas ao saber, que compreende conhecimentos, habilidades, atitudes, valores, e ao saber-fazer, o que induz o leitor mais atento à ideia de que a educação básica deva ser regida pela lógica do mercado de negócios. Em outros termos, é preciso oferecer uma formação elementar que dê subsídios aos alunos a conhecimento e habilidades que lhe são fundamentais para o trabalho. Isso fica evidente até pelo uso de termos da conhecida filosofia $\mathrm{CHA}$ conhecimentos, habilidades e atitudes implementada na área de gestão e administração de negócios. A partir dessas competências, são eleitos os componentes curriculares obrigatórios em uma seleção que lembram as disciplinas tradicionais sem oferecer inovações.

A BNCC também ratifica a perspectiva de uma prática educacional alicerçada no trabalho com tecnologias, cultura digital, de modo a contemplar demandas do mundo do trabalho e da realidade atual como fatores que devem ser correlacionados no ensino básico. Essas considerações incitam a atestar que a base, como o próprio substantivo indica, incita "a assunção de que a educação precisa, pragmaticamente, ser útil para algo que virá. Assim, ela é marquetizada, um bem a ser trocado no mercado futuro." (MACEDO, 2018, p. 28)

Com a inserção mais intensa das tecnologias como "conteúdos" a fazerem parte da base comum curricular, pode-se ainda pensar no quanto essa particularidade incide sobre as demandas de mercado, buscando formar alunos aptos a ingressarem logo no mercado de trabalho. Por outro 
lado, a indicação de novos "conteúdos" a serem incorporados nessa projeção das tecnologias pode fomentar um novo mercado, o de produção de materiais pedagógicos, como os livros didáticos que necessitarão ser atualizados, revistos, adaptados, elaborados para atender a essas novas abordagens. Dessa forma, não se pode desconsiderar que novos parâmetros curriculares alimentam a indústria de editoras de materiais didáticos que têm o governo como seu principal cliente. Sob essa perspectiva,

não sejamos ingênuos, [há] interesses comerciais muito fortes, num país em que a população em idade escolar é de aproximadamente 45 milhões de pessoas (IBGE, 2010). Em 2018, apenas em recursos do tesouro nacional, consta do orçamento o valor de 100 milhões de reais para a implementação da Base. Ela cria um mercado homogêneo para livros didáticos, ambientes instrucionais informatizados, cursos para capacitação de professores, operado por empresas nacionais, mas também por conglomerados internacionais. (MACEDO, 2018, p. 31)

$\mathrm{Na}$ análise da BNCC, também fica logo evidente que a proposta não está articulada ao que há de melhor e mais qualificado processo educacional do mundo, como sugere o texto do Ministro da Educação. Primeiramente, são poucas as opções, em escolas públicas, de educação integral; em segundo lugar, a base não expressa um conjunto de "conhecimentos essenciais e indispensáveis" a que todos os estudantes têm direito, como cita o ministro, já que muitas áreas são desconsideradas na formação. Um exemplo claro: a ausência de literatura enquanto componente curricular obrigatório, tal como o são matemática, artes, língua portuguesa.

No campo específico da área de Linguagens, há ainda outros aspectos que merecem uma observação mais detalhada. Um primeiro fator que chama atenção no texto da BNCC é a divisão da área em apenas quatro componentes curriculares obrigatórios - Língua Portuguesa, Arte, Educação Física e Língua Inglesa (esta apenas para os anos finais do Ensino Fundamental). Com a presença da língua estrangeira somente a partir do sexto ano ignora-se que, quanto mais cedo for o contato com a língua estrangeira, maiores são as chances de aprendizado exitoso de uma segunda língua. No entanto, ainda há a norma de que é obrigatório ensinar inglês nas escolas, perspectiva que não se observa quanto à Literatura, ausente enquanto componente curricular obrigatório.

A inexistência de Literatura enquanto disciplina obrigatória no Ensino Fundamental também não é uma inovação. Na LDBEN, em meados dos anos 1990, ela sequer foi referenciada e, portanto, ignorada enquanto componente curricular. Após duas décadas de LDBEN, nenhum avanço nesse sentido: continua-se presenciando o desprestígio à formação de leitores de literatura. E esse desprestígio está relacionado à ausência da literatura como componente curricular, reforçado ainda pelo desprestígio histórico e crescente no país da leitura literária como algo essencial à formação humana. Ademais, a literatura continua sendo percebida como um objeto de manifestação artística e cultural, da mesma forma que o são letras de hip hop, por exemplo. Isso fica claro na enumeração das competências específicas da área de linguagens, nas quais em nenhuma das seis competências a palavra literatura aparece, o que reforça a tese de que a literatura tem valor menor na proposição de documentos como a BNCC.

Além disso, há a reiteração das linguagens como práticas sociais, algo que não é novo, pois, na década de 1990, os PCNS já indicavam essa orientação conceitual ratificada no texto de 2017. Porém, na BNCC, ficam mais explícitas que, no rol das práticas sociais, o digital deve ser contemplado, inclusive na produção de textos em várias mídias e semioses, pois uma das competências específicas é:

Compreender e utilizar tecnologias digitais de informação e comunicação de forma crítica, significativa, reflexiva e ética nas diversas práticas sociais (incluindo as escolares), para se comunicar por meio das diferentes linguagens e mídias, produzir conhecimentos, resolver problemas e desenvolver projetos autorais e coletivos. (BRASIL, BNCC, 2017, p. 63).

No âmbito das competências do componente de Língua Portuguesa, ficam claras as orientações para trabalho com gêneros textuais, norma padrão, 
leitura, produção e tratamento das linguagens, etc. Dentre as linguagens e gêneros, são citados os relativos a práticas sociais associadas a textos multissemióticos e multimidiáticos. Destaca-se a orientação para, a partir de uma abordagem crítica, "produzir e publicar fotos, vídeos diversos, podcasts, infográficos, enciclopédias colaborativas, revistas e livros digitais" (BRASIL, BNCC, 2017, p. 66), argumentando que o contexto contemporâneo está interligado a essas práticas digitais que também devem ser inseridas na escola.

Se, por um lado, é louvável que o documento sinalize a necessidade de a escola abordar textos digitais em um contexto em que a cultura digital se impõe, por outro, é lamentável reconhecer a indiferença quanto à literatura como objeto essencial á formação do adolescente na segunda etapa do ensino fundamental. Enquanto países como Portugal ${ }^{4}$ manifestam por meio de documento oficial a obrigatoriedade de uma educação literária, destacando o quanto a literatura é indispensável nos currículos escolares, a BNCC brasileira destoa dessa tendência ao relegar à literatura um espaço subliminar. Na BNCC, não se dedica uma atenção especial, como a que é dada ao letramento digital, a práticas de leitura e de apreciação literária como algo essencial à formação na área de Linguagens. A referência à leitura literária aparece apenas no excerto relativo à leitura quando a literatura passa a ser associada a outras atividades. Ou seja, não há um destaque à formação de leitores de literatura como algo fundamental na formação cidadã:

O Eixo Leitura compreende as práticas de linguagem que decorrem da interação ativa do leitor/ouvinte/espectador com os textos escritos, orais e multissemióticos e de sua interpretação, sendo exemplos as leituras

\footnotetext{
4 Em Portugal, em 2015, foi ratificada em documentos programáticos oficiais a obrigatoriedade da educação literária, que deve iniciar desde a educação infantil. Prática comum nas escolas portuguesas, com base em pesquisas sobre promoção da leitura e papel da literatura na formação do sujeito, o país materializou em seus documentos norteadores de ensino daquilo que considera essencial ao aluno: saber ler e compreender textos literários, servindo-se das estratégias de comunicação literária para interpretação e texto. No texto do Programa e Metas Curriculares de Português do Ensino Básico (2015) do país, a leitura da literatura é apresentada como elemento essencial.
}

para: fruição estética de textos e obras literárias; pesquisa e embasamento de trabalhos escolares e acadêmicos; realização de procedimentos; conhecimento, discussão e debate sobre temas sociais relevantes; sustentar a reivindicação de algo no contexto de atuação da vida pública; ter mais conhecimento que permita o desenvolvimento de projetos pessoais, dentre outras possibilidades. (BRASIL, BNCC, 2017, p. 69)

A BNCC não faz menções claras para a abordagem da literatura e de seus diferentes gêneros, porém, quanto aos textos digitais, ela, em diversos momentos do texto, cita exemplos do que é indicado trabalhar nas aulas de Língua Portuguesa, como neste trecho que contempla abordagem sobre reflexão sobre produção e recepção de textos e enumera alguns gêneros textuais: "comentário, carta de leitor, post em rede social, gif, meme, fanfic, vlogs variados, political remix, charge digital, paródias de diferentes tipos, vídeos-minuto, e-zine, fanzine, fanvídeo, vidding, gameplay, walkthroug, detonado, machinima, trailer honesto, playlists" (BRASIL, BNCC, 2017, p. 71).

Por um lado, essa identificação dos gêneros textuais digitais apenas reforça a perspectiva da educação "utilitária" para o mercado de trabalho, como já salientamos no início da abordagem acerca da BNCC. Por outro, observa-se que o (pouco) espaço que a literatura poderia ter na formação de alunos passa a ser "substituído" pelos textos da cultura digital, fazendo supor que estes são mais relevantes do que os literários para uma formação de base do aluno. Nesse ponto, facilmente chega-se à conclusão de que a literatura, cada vez mais, está carente de políticas públicas que a coloquem em relevo. Talvez essa proposição se deva pelo simples fato de se reconhecer o quanto a leitura e a apreciação literária podem promover uma formação mais humana e transformadora do sujeito e da sociedade, como defende Candido (1995; 1972), e, portanto, constituir-se em um instrumento para melhor compreender a condição humana, formando sujeitos para compreender as relações humanas, como pontua Todorov (2009).

Outro exemplo do desprestígio dado à formação de leitores de literatura na BNCC, capazes 
de reconhecer processos de produção e recepção de textos literários - tal como se pontua para os textos digitais - é a segunda menção à literatura na parte de Língua Portuguesa no item "Adesão a práticas de leitura": "Mostrar-se interessado e envolvido pela leitura de livros de literatura, textos de divulgação científica e/ou textos jornalísticos que circulam em várias mídias." (BRASIL, BNCC, 2017, p. 72) (grifos das autoras). "Mostrar-se interessado" não é o mesmo que compreender, analisar, avaliar textos literários e estabelecer relações entre textos literários com outros objetos. Não implica reconhecimento da especificidade da linguagem literária, da apreciação estética do texto e da proposição de sentido para o que é lido e tampouco para a significação da leitura para o sujeito e para a compreensão do mundo, ações que indicariam uma atenção à educação literária. É simplesmente indicar que basta despertar o interesse pela literatura, mas sem desenvolver a habilidade de leitura crítica de textos literários. Ou seja, não é preciso formar leitores literários é o que parece indicar o texto da BNCC.

Tem-se, dessa forma, uma evidente indiferença à necessidade de formação de leitores literários, dando à leitura literária um lugar secundário se comparado com o espaço concedido aos gêneros textuais digitais, por exemplo. A BNCC ratifica seu menosprezo à literatura enquanto gênero textual que merece uma exploração mais aprofundada, consistente e que tem um valor intrínseco à formação básica do aluno. $\mathrm{O}$ documento ignora a potencialidade do texto literário enquanto objeto capaz de promover reflexões, transformações, fruição, interesse pela leitura, indo na contramão do que já se concebe há anos como funções da literatura.

$\mathrm{Na}$ BNCC, a terceira menção à literatura aparece também para sancionar uma abordagem superficial dela na educação básica quando destaca a necessidade de articulação da diversidade de objetos, nos quais são citados os textos literários infantis e juvenis em meio a uma indicação de trabalho relativo a culturas: da consideração da diversidade cultural, de maneira a abranger produções e formas de expressão diversas, a literatura infantil e juvenil, o cânone, o culto, o popular, a cultura de massa, a cultura das mídias, as culturas juvenis etc., de forma a garantir ampliação de repertório, além de interação e trato com o diferente. (BRASIL, BNCC, 2017, p. 73).

A articulação da abordagem da literatura com outras formas de manifestação artística e cultural surge de modo mais específico na seção sobre competências específicas de língua portuguesa para o ensino fundamental. Nesta seção, a literatura é apresentada como um elemento cultural que pode promover o desenvolvimento da fruição estética. Contudo, o texto é lacunar quanto a uma definição de leitura literária e de estratégias de abordagem assim como de gêneros literários que devem ser de contato e apreciação pelos alunos:

Envolver-se em práticas de leitura literária que possibilitem o desenvolvimento do senso estético para fruição, valorizando a literatura e outras manifestações artístico-culturais como formas de acesso às dimensões lúdicas, de imaginário e encantamento, reconhecendo o potencial transformador e humanizador da experiência com a literatura. (BRASIL, BNCC, 2017, p. 85).

A partir dessas constatações que incidem basicamente sobre a forma de exploração de literatura nas escolas, pode-se refletir sobre outros impactos da BNCC, como o que se refere à formação de professores, no caso os de Letras. Quando se têm documentos que se colocam como base, parâmetros reguladores da educação básica, logo é adequado pressupor o quanto eles influenciam a formação de quem forma os alunos da educação básica. Ao verificar o acentuado declínio da literatura enquanto objeto estético a ser contemplado na formação elementar, não é difícil supor que esse fato impacta nos próprios currículos das graduações em Letras. Com tempo de formação e grades cada vez mais enxutos, aderindo a uma profissionalização generalista do saber-fazer, os cursos, embasados em orientações como as da BNCC, tendem a fortalecer o desprestígio dado à literatura na formação de licenciandos. 
Nos cursos de licenciatura em Letras, a educação literária já se revela limitada, com carga horária específica destinada a estudos literários bastante restrita, e sacralizada por uma abordagem da literatura nacional a partir de um viés predominantemente calcado em periodização literária, como mostra a pesquisa de mestrado de Grando (2018) em relação a cursos de Letras considerados como os melhores do Brasil. A partir dessas orientações da BNCC, esse cenário tende a se fortalecer, afinal o que justificaria maior destaque à literatura, se esta se constitui em objeto a ser pouco notabilizado no currículo escolar? Por quais razões se insistiria em prezar pela formação de leitores literários, especializados na compreensão e análise de textos que pouca atenção recebem em documentos norteadores da educação básica?

Além disso, é importante pontuar que a concepção de literatura apresentada na BNCC, como algo capaz de incitar o "desenvolvimento do senso estético para fruição" é reducionista e contrária à grande parte dos estudos teórico-críticos que asseveram uma potencialidade muito maior da literatura, entendida como: objeto de conhecimento, repositório de culturas e expressões identitárias, fonte e documento para a História, forma de leitura de mundo, expressão de visão de mundo e humanização. O fortalecimento da literatura como meio para a fruição, ignorando o potencial formativo e provocativo inerente ao texto literário, também é fator que põe em xeque a pertinência do documento, uma vez que ele apresenta divergência quanto a conceitos relativos à matéria em questão e ignora as pesquisas mais atuais sobre a abordagem do texto literário na sala de aula, mais notadamente nas etapas iniciais de formação escolar.

Por fim, outro impacto decorrente de um lugar limitado e obscuro dado à literatura no BNCC é a real possibilidade de perda da oportunidade de o aluno conhecer a literatura e identificá-la com patrimônio cultural indispensável à sua formação não só como leitor, mas também como sujeito e cidadão. $O$ gradativo espaço menor dedicado à leitura literária nos documentos oficiais que regem o ensino Brasil, a exemplo do texto da BNCC, é um desserviço à formação humana do educando brasileiro e à sua capacitação para a revelação e competências imprescindíveis à vivência em sociedade, como as relacionadas à habilidade de ler, analisar e interpretar textos, relacionando-os com o mundo interior e exterior.

\section{Considerações finais}

Ao se fazer uma síntese das proposições da BNCC no que tange à formação literária dos educandos no ensino fundamental, não há como ignorar o quanto essa base novamente desprestigia a literatura como um direito de todos e como um objeto essencial para a formação. Se a literatura não está explicitamente citada no documento como um eixo específico de formação, que se constitui como uma norma, ela não é considerada fundamental, pois

\begin{abstract}
A Base Nacional Comum Curricular (BNCC) é um documento de caráter normativo que define o conjunto orgânico e progressivo de aprendizagens essenciais que todos os alunos devem desenvolver ao longo das etapas e modalidades da Educação Básica, de modo a que tenham assegurados seus direitos de aprendizagem e desenvolvimento, em conformidade com 0 que preceitua 0 Plano Nacional de Educação (PNE). (BRASIL, BNCC, 2017, p. 7) (grifos nossos)
\end{abstract}

Em tempos em que se acentua a divisão de classes, tem-se desrespeito à democracia, observase o aumento do desemprego e vê-se a qualificação da formação em declínio - tudo acompanhado (e validado) por políticas públicas -, não é de se estranhar que a literatura esteja cada vez mais adormecida nos bancos escolares do ensino fundamental, tal como estimula a BNCC. Em direção inversa ao que se entende como educação literária na escola, a BNCC, em pleno século XXI, seguindo uma lógica de educação para o mercado, é mais uma outra sistematização que apenas dá continuidade a outras perspectivas, como os PCNs e a LDBEN, que já apontam um lugar secundário à educação literária na formação do aluno. 
O apagamento da literatura e por consequência a não obrigatoriedade da formação de leitores literários, a considerar a proposta da BNCC, pode ser fatal no sentido de sedimentar, de forma ainda mais contundente, a educação literária na formação dos alunos - uma educação que já se vê com inúmeros problemas desde os anos 1980 quando surgem pesquisas, como as de Zilbeman (1988), apontando para a crise no ensino de literatura nas escolas. Em uma leitura talvez mais pessimista, o descaso com a abordagem da literatura na formação de crianças e adolescentes pode ser ainda mais devastador porque poucas são as possibilidades de formar leitores de literatura no ensino médio se as leituras literárias não se constituírem em um hábito a ser ampliado nessa etapa final da formação básica.

No ensino fundamental - fase em que a formação do que é base para qualquer cidadão -, a literatura deveria ter um lugar privilegiado justamente para que a imersão no texto literário seja construída de forma prazerosa, motivando a aquisição do hábito de leitura para que este perdure por toda a vida do sujeito. Um preparo necessário para que, na etapa seguinte, a literatura possa ser contemplada não apenas como um gênero textual dentre outros, mas também como objeto estético a ser apreciado com maior capacidade de análise, reflexão e interpretação.

Nessa ótica, é salutar reconhecer que há um longo caminho a percorrer para que a educação literária, no ensino fundamental, possa ter novos parâmetros de para sua abordagem, trazendo a ela um espaço que lhe é devido e necessário ainda mais em um contexto como o atual. É ainda importante observar que a BNCC, que poderia vir como referência para tentar suprir lacunas na educação literária de alunos, propõe um trabalho inverso: indica que literatura é um gênero textual de pouco prestígio educacional e, quiçá, de valor muito menor do que um gif ou um meme, por exemplo.

\section{Referências}

BERENBLUM, Andréa. Por uma política de formação de leitores. Brasília: Ministério da Educação, Secretaria de Educação Básica, 2006.
BORDINI, Maria da Glória. Uma proposta multiculturalista de estudos literários. In: REMÉDIOS, Maria Luiza e ZILBERMAN, Regina. Crítica do tempo presente. Porto Alegre: IEL; Nova Prova, 2005. p. 222-231.

BOSI, Alfredo. Os Estudos Literários na Era dos Extremos. Rio de Janeiro: São Paulo,1994.

BRASIL. Parâmetros Curriculares Nacionais para 0 Ensino Médio. Brasília: Ministério da Educação, 2000. Disponível em: < http://portal.mec.gov.br/seb/arquivos/pdf/blegais.p df>. Acesso em: 5 mar. 2012.

Parâmetros Curriculares Nacionais: língua portuguesa. Brasília: Ministério da Educação, 1997. Disponível em: http://portal.mec.gov.br/seb/arquivos/pdf/portugues .pdf . Acesso em: 5 maio 2014.

Lei no 9.394, de 20 de dezembro de 1996. Estabelece as diretrizes e bases da educação nacional. Disponível em: <http://portal.mec.gov.br/arquivos/pdf/ldb.pdf>. Acesso em: 5 mar. 2013.

CANDIDO, Antonio. O direito à literatura. In: Vários escritos. 3. ed. São Paulo: Duas Cidades, 1995. p. 235-263.

A literatura e a formação do homem. Ciência e cultura, São Paulo, v. 24, n. 9, p. 803-809, set. 1972.

FRANCO JÚNIOR, Arnaldo. Dimensões de leitura e ensino de literatura. In: OURIQUE, João Luís (Org.). Literatura e formação do leitor: escola e sociedade, ensino e educação. ljuí: Ed. Unijuí, 2015. p.207-234.

GRANDO, Patrícia Simone. O (quase não) lugar da literatura na formação de professores de letras. 2018. 102f. Dissertação (Mestrado em Letras Universidade Regional Integrada do Alto Uruguai e das Missões). Frederico Westphalen, 2018.

LOPES, Alice Casemiro. Apostando na construção de currículo. In: AGUIAR, Márcia Angela da S.; DOURADO, Luiz Fernandes (Orgs.). A BNCC na contramão do PNE 2014-2024: avaliação e perspectivas. Recife: ANPAE, 2018. p. 23-27.

MACEDO, Elizabeth. "A base é a base". E o currículo o que é? In: AGUIAR, Márcia Angela da S.; DOURADO, Luiz Fernandes (Orgs.). A BNCC na contramão do PNE 2014-2024: avaliação e perspectivas. Recife: ANPAE, 2018. p. 28-33.

TODOROV, Tzvetan. A literatura em perigo. 2. ed. Trad. Caio Meira. Rio de Janeiro: DIFEL, 2009.

ZILBERMAN, Regina. A leitura e o ensino da literatura. São Paulo: Contexto, 1988. 
A universidade brasileira e o ensino das literaturas de língua portuguesa. In: BORDINI, Maria da Glória; REMÉDIOS, Maria Luiza e ZILBERMAN, Regina. Crítica do tempo presente. Porto Alegre: IEL; Nova Prova, 2005. p. 232-244.

Leitura em crise na escola: as alternativas do professor. Porto Alegre: Mercado Aberto, 1982.

\section{COMO CITAR ESSE ARTIGO}

PORTO, Ana Paula Teixeira; PORTO, Luana Teixeira. O ESPAÇO DO TEXTO LITERÁRIO NA BASE NACIONAL COMUM CURRICULAR NA ETAPA DO ENSINO FUNDAMENTAL. Signo, Santa Cruz do Sul, v. 43, n. 78, nov. 2018. ISSN 1982-2014. Disponível em: <https://online.unisc.br/seer/index.php/signo/article/view/12180>. Acesso em: doi: https://doi.org/10.17058/signo.v43i78.12180. 